\title{
Cis-Divacant Octahedral Fe(II) in a Dimensionally Reduced Family of 2- (Pyridin-2-yl)pyrrolide Complexes
}

Sung-Min Hyun, Kaleb A. Reid, Shaik Waseem Vali, Paul A. Lindahl, and David C. Powers*

$\dagger$ Department of Chemistry, Texas A\&M University, College Station, TX 77843, USA

*powers@chem.tamu.edu

Abstract Four-coordinate transition metal complexes can adopt a diverse array of coordination geometries, with square planar and tetrahedral coordination being the most prevalent. Previously, we reported the synthesis of a trinuclear Fe(II) complex, Fe $\mathbf{T P M}_{2}$, supported by a three-fold symmetric 2-pyridylpyrrolide ligand (i.e., tris(5-(pyridin-2-yl)-1H-pyrrol-2-yl)methane), that featured a rare cis-divacant octahedral (CDO) geometry at each Fe(II) center. Here, a series of truncated 2-pyridylpyrrolide ligands is described that support mono- and binuclear Fe(II) complexes that also exhibit CDO geometries. Metallation of tetradentate ligand bis(5-(pyridin-2yl)-1H-pyrrol-2-yl)methane ( $\left.\mathbf{H}_{2} \mathbf{B P M}\right)$ in THF results in a binuclear complex $\mathbf{F e}_{2}(\mathbf{B P M})_{2}(\mathbf{T H F})_{2}$ in which both $\mathrm{Fe}(\mathrm{II})$ ions are octahedrally coordinated. The coordinated THF solvent ligands are labile: THF dissociation leads to $\mathbf{F e}_{2}(\mathbf{B P M})_{2}$, which features five-coordinate $\mathrm{Fe}(\mathrm{II})$ ions. The FeFe distance in these binuclear complexes can be elongated by ligand methylation. Metalation of bis(5-(6-methylpyridin-2-yl)-1H-pyrrol-2-yl)methane $\left(\mathbf{H}_{2} \mathbf{B P M}^{\mathrm{Me}}\right)$ in THF leads to the formation of four-coordinate, $\mathrm{CDO} F\left(\right.$ II) centers in $\mathbf{F e}\left(\mathbf{B P M}^{\mathbf{M e}}\right)_{2}$. Further ligand truncation affords bidentate ligands 2-(1H-pyrrol-2-yl)pyridine (PyrPyrrH) and 2-methyl-6-(1H-pyrrol-2-yl)pyridine

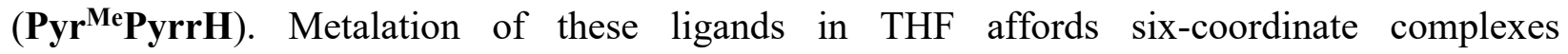
Fe(PyrPyrr $)_{2}(\mathrm{THF})_{2}$ and $\mathbf{F e}\left(\mathrm{Pyr}^{\mathrm{Me} P y r r}\right)_{2}$ (THF $)_{2}$. Dissociation of labile solvent ligands provides access to four-coordinate Fe(II) complexes. Ligand disproportionation at Fe(PyrPyrr)2 results in the formation of $\mathbf{F e}(\mathbf{P y r P y r r})_{3}$ and $\mathrm{Fe}(0)$. Ligand methylation suppresses this disproportionation and enables isolation of $\mathbf{F e}\left(\mathbf{P y r}^{\mathrm{Me}} \mathbf{P y r r}\right)_{2}$, which is rigorously CDO. Complete ligand truncation, by separating the 2-pyridylpyrrolide ligands into the constituent monodentate pyridyl and pyrrolide donors, affords $\mathbf{F e}(\mathbf{P y r})_{2}$ (Pyrr) $)_{2}$ in which the Fe(II) is tetrahedrally coordinated. Computational analysis indicates that the potential energy surface that dictates the coordination geometry in this family of four-coordinate complexes is fairly flat in the vicinity of CDO coordination. These synthetic studies provide the structural basis to explore the implications of CDO geometry on Fecatalyzed reactions. 


\section{INTRODUCTION}

Exerting synthetic control over the coordination geometry of transition metal complexes is critical to eliciting specific physical and chemical properties and thus synthetic efforts to access unique coordination geometries provide opportunities to develop new reactivity patterns. ${ }^{1-3}$ Fourcoordinate complexes are of particular interest due to the rich diversity of geometries that are accessible (Figure 1a). Square planar and tetrahedral coordination modes are the most commonly encountered geometries for four coordinate species, and ligand design features that differentiate these geometries have been the topic of extensive investigation. ${ }^{4-6}$ In general, tetrahedral coordination is sterically preferred and is thus favored for large ligands and small transition metal ions. Square planar coordination is sterically disfavored but can afford significant ligand field stabilization energy. Beyond tetrahedral and square planar geometries, less common see-saw geometries are also available to four-coordinate ions. Cis-divacant octahedral (CDO) and monovacant trigonal bipyramidal (MTB) are see-saw geometries that differ in the bond angle $(\theta)$ between the equatorial ligands $\left(\mathrm{CDO}=90^{\circ}\right.$ and $\left.\mathrm{MTB}=120^{\circ}\right)$. While these geometries are potentially attractive platforms for application in catalysis because they feature sterically accessible coordination sites poised to engage substrates, they are encountered much less often than either tetrahedral or square planar geometries.

Perfect adherence to the idealized structures illustrated in Figure 1a is uncommon and in the context of heteroleptic coordination complexes not possible. The extent of structural distortion from the idealized geometries can be hard to accurately describe, and thus a number of algorithms have been developed that aim to quantify the nature and extent of geometrical distortion. ${ }^{7-12}$ Here we utilize two approaches to quantifying the geometries of four-coordinate complexes that are commonly encountered: $\tau_{4}$ values ${ }^{13}$ and continuous shape analysis. ${ }^{14-16}$ The $\tau_{4}$ metric is derived 
from observed metal-ligand (M-L) bond angles to describe the coordination geometry of fourcoordinate complexes; ${ }^{13} \tau_{4}$ values that characterize limiting four-coordinate geometries are listed in Figure 1a. Similarly, continuous shape analysis has been advanced as an approach to evaluate the structural deviations of observed coordination geometries from idealized polyhedra. ${ }^{14-16}$

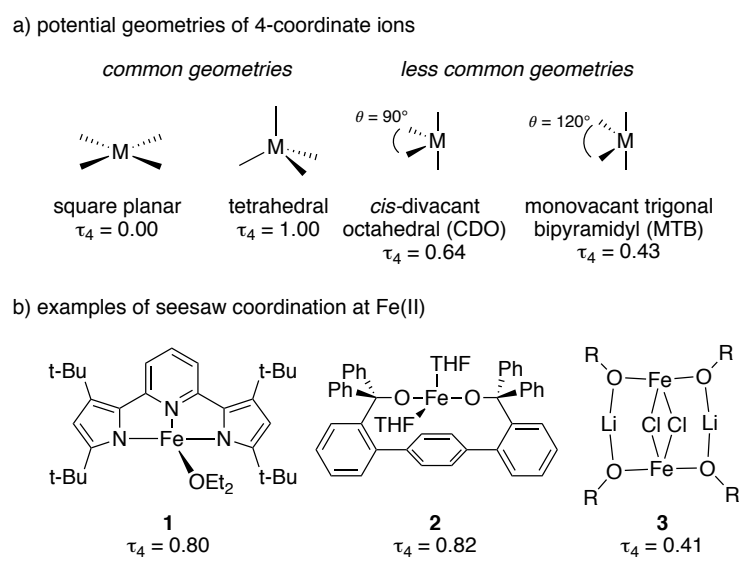

Figure 1. (a) Four-coordinate metal ions most commonly adopt tetrahedral or square planar coordination geometries. Distortions of these geometries gives rise to see-saw structures with limiting cis-divacant octahedral (CDO) or monovacant trigonal bipyramidyl (MTB) geometries. The $\tau_{4}$ parameter utilizes experimentally obtained bond angles to describe the geometry of four-coordination ions. (b) Selected four-coordinate Fe(II) complexes that feature see-saw coordination with the crystallographically derived $\tau_{4}$ values.

In the context of Fe(II) chemistry, a small family of four-coordinate complexes that display highly distorted seesaw geometries have been reported (Figure 1b). Pincer-supported Fe(II) complex 1 displays approximately CDO geometry and participates in two-electron oxidative chemistry upon treatment with adamantyl azide to afford the corresponding Fe(IV) imide complex. ${ }^{17}$ The observation of CDO coordination in complex 1 was ascribed to minimization of steric interactions that would be encountered in a potential square planar complex. Similarly, transchelating bis-alkoxide complex 2 features an Fe(II) center that displays approximately CDO coordination. ${ }^{18}$ Alkoxide-supported complex $\mathbf{3}$ also displays see-saw geometry at the Fe(II) center, which is best described as MTB, although this geometry likely arises due to the combination of bridging chloride ligands and the presence of templating $\mathrm{Li}^{+}$ions. ${ }^{19}$ 
In 2020 we reported the synthesis and characterization of a trinuclear $\mathrm{Fe}(\mathrm{II})$ complex, $\mathbf{F e}_{3} \mathbf{T P M}_{2}$, assembled from Fe(II) and the three-fold symmetric ligand tris(5-(pyridin-2-yl)- $1 H$ pyrrol-2-yl)methane $\left(\mathbf{H}_{3} \mathbf{T P M}\right.$, Figure 2). ${ }^{20}$ Each of the Fe(II) ions in this complex displayed closeto-idealized CDO geometry ( $\left.\tau_{4}=0.60\right)$. Attempts to leverage trinuclear complex $\mathbf{F e}_{3} \mathbf{T P M} \mathbf{M}_{2}$, which features a central molecular void in which each of the ions presents two vacant coordination sites, for small molecule binding or activation were unsuccessful. To both evaluate the structural origins of the CDO geometry and access more sterically accessible CDO transition metal sites, we have pursued synthetic studies of a series of dimensionally reduced ligands, namely bis(5-(pyridin-2yl)-1H-pyrrol-2-yl)methane (H2 $\mathbf{B P M}), 2$-(1H-pyrrol-2-yl)pyridine (PyrPyrrH) and methylated analogues thereof. Here, we report a family of mono- and binuclear complexes of Fe(II) featuring CDO coordination geometry. We demonstrate the critical role of ligand structure and solvation in accessing the four-coordinate $\mathrm{CDO}$ complexes. Further, we demonstrate that the potential energy surface that gives rise to the $\mathrm{CDO}$ coordination geometry is fairly flat, which suggests that small structural perturbations can manifest as significant structural changes about this geometry. 

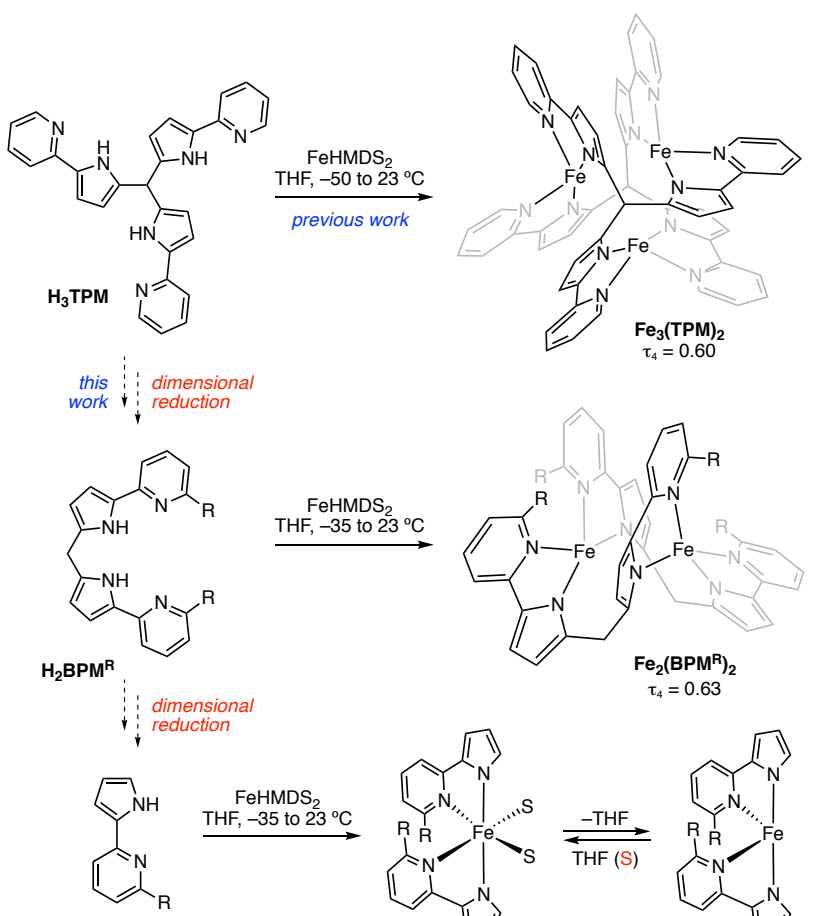

Pyr ${ }^{\mathrm{R} P y r H}$
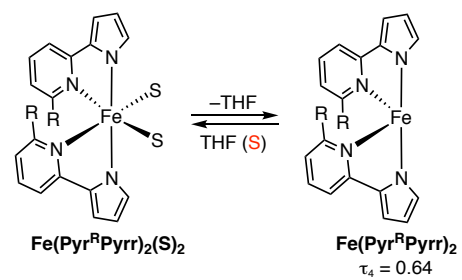

Figure 2. Previously, trinuclear complex $\mathrm{Fe}_{3} \mathrm{TPM}_{2}$ was prepared from three-fold symmetric ligand $\mathrm{H}_{3} \mathrm{TPM}$ and features three $\mathrm{CDO} \mathrm{Fe}(\mathrm{II})$ centers. In this work, dimensional reduction from $\mathbf{H}_{3}$ TPM to two-fold symmetric $\mathrm{H}_{2} \mathbf{B P M}$ and to 2(pyridin-2-yl)pyrrole PyrPyrrH was carried out and CDO coordination was maintained across this simpler ligand framework.

\section{RESULTS}

of $\mathrm{Fe}$ (II) complexes, we prepared a series of truncated ligands in which pyridylpyrrole arms were removed from $\mathbf{H}_{3}$ TPM. Bidentate ligands 2-(1H-pyrrol-2-yl)pyridine (PyrPyrrH) and 2methyl-6-(1H-pyrrol-2-yl)pyridine (Pyr $\left.{ }^{\mathrm{Me}} \mathbf{P y r r H}\right)$ were prepared by Pd-catalyzed cross coupling of zinc pyrrolide with 2-bromopyridine and 6-methyl-2-bromopyridine, respectively (Figure 3). ${ }^{21}$ Condensation of each of these compounds with 0.5 equivalents of paraformaldehyde in the presence of $\mathrm{InCl}_{3}$ yielded tetradentate ligands 2-(1H-pyrrol-2-yl)pyridine $\left(\mathbf{H}_{2} \mathbf{B P M}\right)$ and bis(5-(6methylpyridin-2-yl)-1H-pyrrol-2-yl)methane $\left(\mathbf{H}_{2} \mathbf{B P M}^{\mathrm{Me}}\right)$. Each of the ligands was characterized by ${ }^{1} \mathrm{H}$ and ${ }^{13} \mathrm{C}$ NMR spectroscopies as well as high-resolution mass spectrometry (Figure S1-S5). 


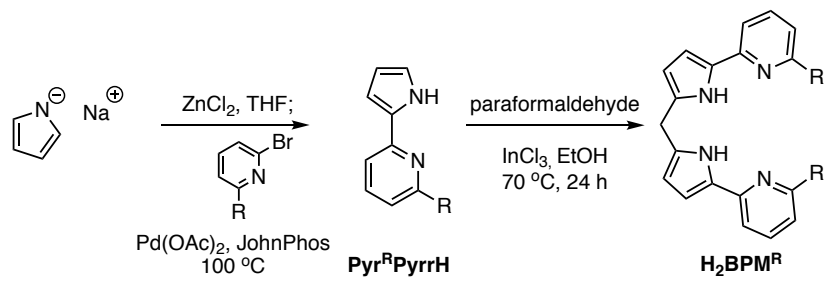

Figure 3. Synthesis of 2-(pyridin-2-yl)pyrrole ligands. Bidentate ligands PyrR PyrrH were prepared via Pd-catalyzed coupling of $\mathrm{Zn}$ pyrrolide with 2-bromopyridines. Tetradentate ligands $\mathbf{H}_{2} \mathbf{B P M}^{\mathrm{R}}$ were prepared by condensation of Pyr ${ }^{\mathrm{R}}$ PyrrH with paraformaldehyde in the presence of $\mathrm{InCl}_{3}$.

Synthesis of Binuclear Fe(II) Complexes. Metallation of $\mathbf{H}_{2} \mathbf{B P M}$ was accomplished by treating a THF solution of the ligand with $\mathrm{FeHMDS} 2$ at $-35{ }^{\circ} \mathrm{C}$ and then allowing the reaction mixture to slowly warm to $23{ }^{\circ} \mathrm{C}$ (Figure 4). $\mathbf{F e}_{2}(\mathbf{B P M})_{2}(\mathbf{T H F})_{2}$ was isolated as an orange crystalline solid following vapor diffusion of pentane into the reaction mixture at $-35^{\circ} \mathrm{C}$. The ${ }^{1} \mathrm{H}$ NMR spectrum of $\mathbf{F e}_{2}(\mathbf{B P M})_{2}$ (THF)2 displays eight paramagnetically shifted ${ }^{1} \mathrm{H}$ NMR peaks from 8-135 ppm (Figures S6-S7). Consistent with the dark orange color of the sample, the UV-vis spectrum measured in THF displays a broad at $480 \mathrm{~nm}\left(\varepsilon=1.0 \times 10^{3} \mathrm{M}^{-1} \mathrm{~cm}^{-1}\right.$; Figure S8). High-resolution mass spectrometry was consistent with an $\mathrm{Fe}_{2} \mathrm{~L}_{2}$ aggregate $\left(\mathrm{HRMS}-\mathrm{ESI}^{+}\right.$: calcd for $\left[\mathrm{Fe}_{2}(\mathrm{BPM})_{2}\right]^{+}$ 708.1135; expt. 708.1115). The magnetic susceptibility was evaluated by Evan's method, which provided $\mu_{\mathrm{B}}=6.9$, which is consistent with an $\mathrm{S}=3$ complex. The ${ }^{57} \mathrm{Fe}$ Mössbauer spectrum obtained for a sample of this compound (Figure S9) could not be adequately simulated with less than three quadrupole doublets, which we attribute to solvent dissociation equilibria giving rise to a mixture of related binuclear $\mathrm{Fe}_{2}$ complexes (vide infra). 


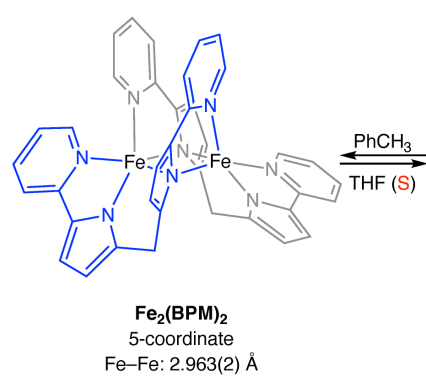

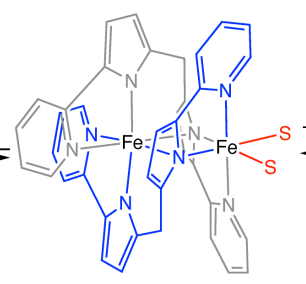

$\mathrm{Fe}_{2}(\mathrm{BPM})_{2}(\mathrm{THF})_{2}$

6 -coordinate $\mathrm{Fe}$

$\mathrm{Fe}-\mathrm{Fe}: 3.1551(6) \AA$

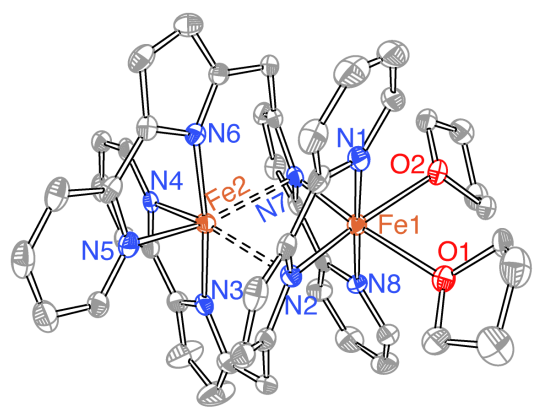

$\mathrm{Fe}_{2}(\mathrm{BPM})_{2}(\mathrm{THF})_{2}$

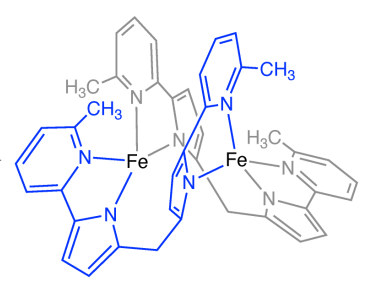

$\mathrm{Fe}_{2}\left(\mathrm{BPM}^{\mathrm{Me}}\right)_{2}$ Fe-Fe: 3.63343(4) $\AA$

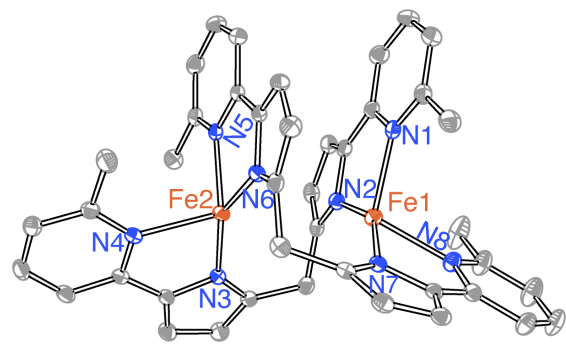

$\mathrm{Fe}_{2}\left(\mathrm{BPM}^{\mathrm{Me}}\right)_{2}$

Figure 4. Top: Synthesis of binuclear $\mathrm{Fe}(\mathrm{II})$ complexes. Metallation of $\mathbf{H}_{2} \mathbf{B P M}$ with $\mathrm{Fe}(\mathrm{HMDS})_{2}$ affords $\mathrm{Fe}_{2}(\mathrm{BPM})_{2}(\mathrm{THF})_{2}$ in which both $\mathrm{Fe}(\mathrm{II})$ centers are six-coordinate. Recrystallization from toluene affords $\mathrm{Fe} \mathrm{e}_{2}(\mathrm{BPM})_{2}$ in which the THF ligands have dissociated and both $\mathrm{Fe}(\mathrm{II})$ centers are five-coordinate. Metallation of $\mathbf{H}_{2} \mathbf{B P M}{ }^{\mathrm{Me}}$ with $\mathrm{Fe}(\mathrm{HMDS})_{2}$ affords $\mathrm{Fe}_{\mathbf{2}}\left(\mathrm{BPM}^{\mathrm{Me}}\right)_{\mathbf{2}} \mathbf{T H H}_{\mathbf{2}}$ in which both $\mathrm{Fe}(\mathrm{II})$ centers are four-coordinate. Ligands are color-coded gray and blue to highlight the coordination mode of each ligand. Bottom: Displacement ellipsoid plots (50\% probability) of the prepared binuclear Fe(II) complexes. Selected bond distances (Å): Fe 2 (BPM) 2 Fe1-Fe1' = 2.963(2), Fe1-N3' = 2.031(4), and Fe1-N3 = 2.381(6); $\mathrm{Fe}_{2}(\mathrm{BPM})_{2}(\mathrm{THF})_{2} \mathrm{Fe} 1-\mathrm{Fe} 2=3.1551(6)$, Fe1-N7 = 2.105(4), and Fe2-N7 = 2.496(3); $\mathrm{Fe}_{2}\left(\mathrm{BPM}^{\mathrm{Me}}\right)_{2} \mathrm{Fe} 1-\mathrm{Fe} 2=3.6343(4), \mathrm{Fe} 1-\mathrm{N} 2=1.992(2), \mathrm{Fe} 1-\mathrm{N} 3=3.060(2)$.

Table 1. Summary of selected metrical parameters for $\mathrm{Fe}_{2}(\mathrm{BPM})_{2}(\mathrm{THF})_{2}, \mathrm{Fe}_{2}(\mathrm{BPM})_{2}$, and $\mathrm{Fe}_{2}\left(\mathrm{BPM}{ }^{\mathrm{Me}}\right)_{2}$.

\begin{tabular}{lccc}
\hline & $\mathrm{Fe}_{2}(\mathrm{BPM})_{2}(\mathrm{THF})_{2}$ & $\mathrm{Fe}_{2}(\mathrm{BPM})_{2}$ & $\mathrm{Fe}_{2}\left(\mathrm{BPM}^{\mathrm{Me}}\right)_{2}$ \\
\hline $\mathrm{Fe} \bullet \bullet \bullet \mathrm{Fe}$ & $3.1551(6)$ & $2.963(2)$ & $3.6343(4)$ \\
$\mathrm{Fe} 1-\mathrm{N}_{\text {pyrr }}{ }^{\mathrm{a}}$ & $2.118(2)$ & & \\
$\mathrm{Fe} 2-\mathrm{N}_{\text {pyrr }}{ }^{\mathrm{b}}$ & $2.029(1)$ & $2.031(4)$ & $1.9972(7)$ \\
$\mathrm{Fe}-\mathrm{N}_{\text {pyr }, \pi}$ & $2.448(1)^{\mathrm{c}}$ & $2.381(6)^{\mathrm{d}}$ & --- \\
$\mathrm{Fe} 1-\mathrm{N}_{\text {pyr }} \mathrm{e}^{\mathrm{e}}$ & $2.202(1)$ & $2.176(4)$ & $2.1304(8)$ \\
$\mathrm{Fe} 2-\mathrm{N}_{\text {pyr }}{ }^{\mathrm{f}}$ & $2.149(2)$ & & \\
\hline
\end{tabular}

${ }^{a}$ Average bond distance of Fe1-N2 and Fe1-N7 (Fe1-N3'). ${ }^{\mathrm{b}}$ Average bond distance of Fe2-N3 (Fe1'-N3) and Fe2N6 (Fe1'-N2'). 'Average bond distance of Fe2-N2 and Fe2-N7. 'Average bond distance of Fe1-N3' and Fe1'-N3. ${ }^{\mathrm{e}}$ Average bond distance of $\mathrm{Fe} 1-\mathrm{N} 1$ and $\mathrm{Fe} 1-\mathrm{N} 8\left(\mathrm{Fe} 1-\mathrm{N} 4{ }^{\prime}\right)$. 'Average bond distance of $\mathrm{Fe} 2-\mathrm{N} 4(\mathrm{Fe} 1$ '-N4) and Fe2N5 (Fe1'-N1').

Crystallization of $\mathbf{F e}_{2}(\mathbf{B P M})_{2}$ (THF) $)_{2}$ by vapor diffusion of pentane into THF solution at -35

${ }^{\circ} \mathrm{C}$ afforded single crystals of $\mathbf{F e}_{2} \mathbf{B P M}_{2}$ (THF)2 (Figure 4). $\mathbf{F e}_{2} \mathbf{B P M}_{2}(\mathbf{T H F})_{2}$ crystallizes in the

triclinic space group $P-1$ with two whole molecules and three THF molecules residing in the 
crystallographically independent unit. The $\mathrm{Fe}(\mathrm{II})$ centers in $\mathrm{Fe}_{2} \mathrm{BPM}_{2}(\mathrm{THF})_{2}$ are both sixcoordinate. Fe1 is ligated by pyridylpyrrolide moieties of two different ligands, such that the pyridyl donors are mutually trans, and by two THF donors. The pyrrolide donors to Fe1 are $\sigma-$ bound and the Fe1- $\mathrm{N}_{\text {pyrr }}$ distance is 2.118(2) $\AA$ (i.e., average Fe-N of Fe1-N2 and Fe1-N7), which is consistent with the Fe-N distance expected of a high-spin $\mathrm{Fe}(\mathrm{II})$ ion. ${ }^{22,}{ }^{23} \mathrm{Fe} 2$ is also supported by pyridylpyrrolide donors of two different ligands, although unlike Fe1, the pyridyl donors to Fe2 are mutually cis. The remaining two coordination sites are occupied by $\pi$-interactions with the pyrrolide ligands that are $\sigma$-bound to $\mathrm{Fe} 1 ; \mathrm{Fe} 2-\mathrm{N}_{\text {pyrr }}=2.448(1) \AA$ (i.e., average of $\mathrm{Fe} 2-\mathrm{N} 2$ and Fe2-N7). The Fe-Fe distance (3.1551(6) Å) in $\mathbf{F e}_{2}(\mathbf{B P M})_{2}(\mathbf{T H F})_{2}$. Based on this distance, the formal shortness ratio ( $\mathrm{fsr}$ ), ${ }^{24,25}$ which is the ratio of the interatomic distance divided by the sum of the covalent radii, ${ }^{26}$ is 1.35 . Because the value is significantly greater than 1 we do not formulate any $\mathrm{Fe}-\mathrm{Fe}$ bonding in $\mathbf{F e}_{2}(\mathbf{B P M})_{2}(\mathbf{T H F})_{2}$.

The THF ligands of $\mathbf{F e}_{2}(\mathbf{B P M})_{2}(\mathbf{T H F})_{2}$ are labile. Recrystallization of $\mathbf{F e}_{2}(\mathbf{B P M})_{2}(\mathbf{T H F})_{2}$ from toluene afforded a single crystal of $\mathbf{F e}_{2}(\mathbf{B P M})_{2}$, in which the binuclear core in conserved but the previously coordinated THF ligands are no longer present (Figure 4). Loss of coordinated solvent is accompanied by ligand rearrangement: The coordination sphere is comprised of pyridylpyrrolide moieties from two different ligand molecules with one of the pyrrolide donors adopting a bridging position. The Fe centers in $\mathbf{F e}_{2}(\mathbf{B P M})_{2}$ are symmetry equivalent and fivecoordinate. Both the $\tau_{5}$ parameter of $0.156^{27,28}$ and continuous shape measurement (CShM) calculations, ${ }^{14-16}$ are consistent with distorted square pyramidal coordination of both Fe centers $\left(\tau_{5}\right.$ for an idealized square pyramid is 0). ${ }^{13,} 27$ The Fe-Fe separation in $\mathbf{F e}_{2}(\mathbf{B P M})_{2}(2.963(2) \AA)$ is slightly shorter than that observed in $\mathbf{F e}_{2}(\mathbf{B P M})_{2}(\mathbf{T H F})_{2}$, but the formal shortness ratio (fsr $\left.=1.27\right)$ is again inconsistent with meaningful Fe-Fe bonding. Consistent with symmetry equivalent Fe 
centers, the ${ }^{57} \mathrm{Fe}$ Mössbauer spectrum of $\mathbf{F e}_{2}(\mathbf{B P M})_{2}$ displays a single quadrupole doublet with isomer shift of $\delta=0.962$ and a quadrupole splitting of $\left|\Delta \mathrm{E}_{\mathrm{Q}}\right|=3.054$ (Figure 5a). In addition, UVvis spectroscopy of $\mathrm{Fe}_{2} \mathrm{BPM}_{2}$ measured in toluene shows absorption at 493 and $525 \mathrm{~nm}(\varepsilon=1.0 \times$ $10^{3}$ and $8.1 \times 10^{2} \mathrm{M}^{-1} \mathrm{~cm}^{-1}$, respectively), which reflects a red shift of $\mathrm{d}-\mathrm{d}$ transition band upon removal of coordinated solvent. The removal of THF is reversible: Recrystallization of $\mathrm{Fe}_{2}(\mathbf{B P M})_{2}$ from THF affords $\mathbf{F e}_{2}(\text { BPM })_{2}(\text { THF })_{2}$.

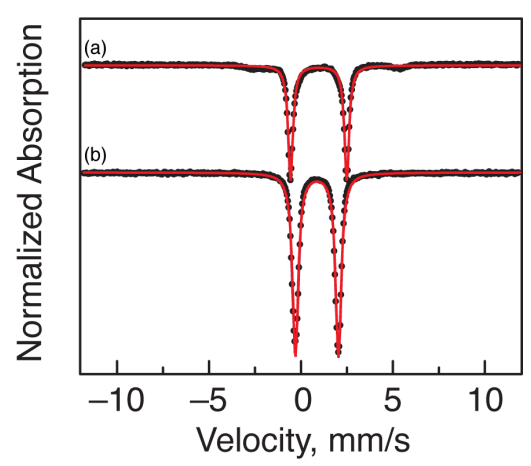

Figure 5. ${ }^{57} \mathrm{Fe}$ Mössbauer spectra of binuclear Fe(II) complexes measured at $5 \mathrm{~K}$. (a) $\mathrm{Fe}_{2}(\mathrm{BPM})_{2}$ displays a single quadrupole doublet with $\delta=0.962,\left|\Delta \mathrm{E}_{Q}\right|=3.054, \gamma=0.314$. (b) $\mathbf{F e}_{2}\left(\mathrm{BPM}^{\mathrm{Me}}\right)_{2}$ displays a single quadrupole doublet with $\delta=0.868,\left|\Delta \mathrm{E}_{\mathrm{Q}}\right|=2.339, \gamma=0.373$. $\delta$, isomer shift; $\left|\Delta \mathrm{E}_{\mathrm{Q}}\right|$, quadrupole splitting; $\gamma$, linewidth.

We hypothesized that ligand methylation (i.e., Pyr ${ }^{\text {Me }} \mathbf{P y r r H}$ ) would introduce interligand steric interactions that would result in $\mathrm{Fe}-\mathrm{Fe}$ elongation that could eliminate the $\mathrm{Fe}-\mathrm{N}_{\text {pyrr }} \pi$-interactions present in $\mathbf{F e}_{2}(\mathbf{B P M})_{2}$ and give rise to four-coordinate $\mathrm{Fe}(\mathrm{II})$ ions. We validated this hypothesis by preparing $\mathbf{F e}_{2}\left(\mathbf{B P M}^{\mathrm{Me}}\right)_{2}$ from $\mathbf{H}_{2} \mathbf{B P M}^{\mathrm{Me}}$ and $\mathrm{Fe}(\mathrm{HMDS})_{2}$ (Figure 4). Crystallization via vapor diffusion of pentane into THF solution yielded a dark orange crystalline solid which displayed 7 paramagenetically shifted ${ }^{1} \mathrm{H}$ NMR peaks (Figure S10-S11); Evan's method provides $\mu_{\mathrm{B}}=6.8$ which is consistent with an $\mathrm{S}=3$ complex. The UV-vis spectrum measured in THF displayed absorptions at 492 and $523 \mathrm{~nm}\left(\varepsilon=1.1 \times 10^{3}\right.$ and $9.1 \times 10^{2} \mathrm{M}^{-1} \mathrm{~cm}^{-1}$, respectively; Figure S12), which are similar to those observed for $\mathbf{F e}_{2}(\mathbf{B P M})_{2}$ in toluene. High-resolution mass spectrometry 
was consistent with binuclear iron compound $\mathbf{F e}_{2}\left(\mathbf{B P M}^{\mathrm{Me}}\right)_{2}\left(\mathrm{HRMS}-\mathrm{ESI}^{+}[\mathrm{M}]^{+}\right.$calcd. 764.1756; expt. 764.1736; $[\mathrm{M}+\mathrm{H}]^{+}$calcd 765.1835; expt. 765.1807). The ${ }^{57} \mathrm{Fe}$ Mössbauer spectrum of displays a single quadrupole doublet with $\delta=0.868$ and $\left|\Delta \mathrm{E}_{\mathrm{Q}}\right|=2.339$ (Figure 5b). These parameters are similar to those obtained for trinuclear complex $\mathbf{F e}_{3}(\mathbf{T P M})_{2}\left(\delta=0.835\right.$ and $\left|\Delta \mathrm{E}_{\mathrm{Q}}\right|=$ 2.171) and suggested the two compounds may feature similar CDO coordination at the $\mathrm{Fe}(\mathrm{II})$ sites.

A single crystal of $\mathbf{F e}_{2}\left(\mathbf{B P M}^{\mathrm{Me}}\right)_{2}$ was obtained by a vapor diffusion of pentane into THF solution. ${ }^{29}$ Refinement of X-ray diffraction data collected at $110 \mathrm{~K}$ reveals a binuclear complex in which each of the Fe centers is four-coordinate. The Fe-Fe distance is significantly elongated (3.6342(4) $\left.\AA, f_{s r}=1.56\right)$ relative to the unmethylated analogue $\mathbf{F e}_{2}(\mathbf{B P M})_{2}(2.963(2) \AA)$. The $\mathrm{Fe}-$ $\mathrm{Fe}$ elongation results in the removal of the $\pi$-interactions that are observed in $\mathbf{F e}_{2}(\mathbf{B P M})_{2}$; in $\mathbf{F e}_{2}\left(\mathbf{B P M}^{\mathrm{Me}}\right)_{2}$ the $\mathrm{Fe}-\mathrm{N}$ distances are 3.064(1) $\AA$ (average of Fe1-N3 and Fe2-N7) and 4.383(1) $\AA$ (average of Fe1-N6 and Fe2-N2) Å. CShM analysis indicate each Fe(II) center adopts a slightly distorted CDO geometry (Table 2), and $\tau_{4}$ values of 0.62 and 0.63 for each metal center are also consistent with CDO geometry ( $\tau_{4}=0.640$ for an idealized CDO geometry) ${ }^{13}$

Synthesis of Mononuclear Fe(II) Complexes. Mononuclear complex $\mathbf{F e}(\mathbf{P y r P y r r})_{2}(\mathbf{T H F})_{2}$ was obtained as a yellow crystalline solid by metallation of PyrPyrrH with $\mathrm{Fe}(\mathrm{HMDS})_{2}$ in THF following by vapor diffusion of pentane into the crude reaction mixture (Figure 6). The ${ }^{1} \mathrm{H}$ NMR spectrum of $\mathbf{F e}(\mathbf{P y r P y r r})_{2}$ (THF) 2 displays six paramagnetically shifted ${ }^{1} \mathrm{H}$ NMR signals from 28 to $140 \mathrm{ppm}$ in $d_{8}$-THF (Figures S13-S14). The UV-vis spectrum of $\mathbf{F e}(\mathbf{P y r P y r r})_{2}(\mathbf{T H F})_{2}$ measured in THF displays a broad tailing UV-vis absorption that ends at $\sim 530 \mathrm{~nm}$ and no distinct lower energy absorptions (Figure S15). Evan's method affords a magnetic moment of $4.5 \mu_{\mathrm{B}}$, which is consistent with an $\mathrm{S}=2$ spin state. The ${ }^{57} \mathrm{Fe}$ Mössbauer spectrum displays a single quadrupole doublet with $\delta=1.141$ and $\left|\Delta \mathrm{E}_{\mathrm{Q}}\right|=2.450$ (Figure 7a). A single crystal of 
Fe(PyrPyrr $)_{2}(\text { THF })_{2}$ was obtained from a concentrated THF/pentane solution. Refinement of the single-crystal X-ray diffraction data provides the structure illustrated in Figure 6. The octahedra coordination sphere of the Fe(II) center is composed of two pyridylpyrrolide ligands and two THF molecules. The $\mathrm{Fe}-\mathrm{N}_{\text {pyrr }}$ distances (avg. 2.089(2) $\AA$ ) are consistent with an $\mathrm{S}=2$ complex. $^{30}$

Table 2. CShM for four-coordinate iron(II) complexes using SHAPE program, which calculates deviations of a set of atomic positions relative to the vertices of idealized polygons or polyhedra on the definition of minimal distortion paths and generalized interconversion coordinates. ${ }^{14,31,32}$

\begin{tabular}{|c|c|c|c|c|}
\hline \multirow{3}{*}{$\begin{array}{l}\text { Idealized } \\
\text { Geometry }\end{array}$} & \multicolumn{4}{|c|}{ Calculated Deviation } \\
\hline & \multicolumn{2}{|c|}{$\mathrm{Fe}_{2}\left(\mathrm{BPM}^{\mathrm{Me}}\right)_{2}$} & \multirow{2}{*}{$\mathrm{Fe}\left(\text { Pyr }^{\text {MePyrr }}\right)_{2}$} & \multirow{2}{*}{$\mathrm{Fe}(\mathrm{Pyr})_{2}(\mathrm{Pyrr})_{2}$} \\
\hline & $\mathrm{Fe} 1$ & $\mathrm{Fe} 2$ & & \\
\hline Sq. Planar & 23.132 & 25.339 & 23.982 & 31.655 \\
\hline Tetrahedral & 6.398 & 6.204 & 5.958 & 0.356 \\
\hline $\mathrm{CDO}$ & 5.054 & 5.204 & 5.215 & 6.992 \\
\hline MTB & 6.802 & 6.587 & 6.733 & 2.804 \\
\hline$\tau_{4}$ & 0.621 & 0.630 & 0.640 & 0.902 \\
\hline
\end{tabular}

Attempts to access four-coordinate Fe(PyrPyrr $)_{2}$ by recrystallization of Fe(PyrPyrr $)_{2}(\mathrm{THF})_{2}$ from toluene were unsuccessful. Instead, disproportionation afforded dark red crystals of Fe(III) complex Fe(PyrPyrr)3 and black amorphous powder Fe(0); the spectral data of Fe(PyrPyrr)3 prepared by disproportionation of $\mathbf{F e}(\mathbf{P y r P y r r})_{2}$ (THF) $)_{2}$ are consistent with those obtained for a sample of $\mathbf{F e}(\mathbf{P y r P y r r})_{3}$ that was independently synthesized from PyrPyrrH, $\mathrm{FeCl}_{3}$, and NaHMDS. Single crystals obtained following disproportionation of $\mathbf{F e}(\mathbf{P y r P y r r})_{2}(\mathbf{T H F})_{2}$ and from independently prepared Fe(PyrPyrr) ${ }_{3}$ displayed identical unit cells. The $\mathrm{Fe}-\mathrm{N}_{\text {pyrr }}$ distances determined from the X-ray structure of Fe(PyrPyrr) 3 (1.905(2) A) are comparable to reported Fe(III) complexes. ${ }^{33}$ For solution-phase characterization of Fe(PyrPyrr)3, see Supporting Information (Figure S16-S18).

Metallation of Pyr ${ }^{\text {Me }}$ PyrrH with Fe(HMDS) $)_{2}$ followed by vapor diffusion of pentane into the crude metalation reaction mixture at $-35^{\circ} \mathrm{C}$ afforded $\mathbf{F e}\left(\mathbf{P y r}^{\mathrm{Me}} \mathbf{P y r r}\right)_{2}(\mathbf{T H F})_{2}$ as a yellow solid. Solution-phase characterization of $\mathbf{F e}\left(\mathbf{P y r}^{\mathrm{Me}} \mathbf{P y r r}\right)_{2}(\mathbf{T H F})_{2}$ is similar to that obtained for 
$\mathbf{F e}(\mathbf{P y r P y r r})_{2}(\mathrm{THF})_{2}$ : The ${ }^{1} \mathrm{H}$ NMR spectrum displays 7 paramagnetic peaks from -25 to $64 \mathrm{ppm}$ and the UV-vis spectrum displays weak absorptions at 470 and $496 \mathrm{~nm}\left(\varepsilon=3.7 \times 10^{2}\right.$ and $2.2 \times$ $10^{2} \mathrm{M}^{-1} \mathrm{~cm}^{-1}$, respectively; Figure S19-S21). Evan's method (4.9 $\left.\mu_{\mathrm{B}}\right)$ is consistent with an $\mathrm{S}=2$ complex and the ${ }^{57} \mathrm{Fe}$ Mössbauer spectrum displays a single quadrupole doublet with $\delta=1.020$ $\left(\left|\Delta \mathrm{E}_{\mathrm{Q}}\right|=3.20\right)$ (Figure $\left.7 \mathrm{~b}\right)$. The structure of $\mathbf{F e}\left(\mathbf{P y r} \mathbf{r}^{\mathrm{Me}} \mathbf{P y r r}\right)_{2}(\mathbf{T H F})_{2}$ was determined by refinement of X-ray diffraction data collected at $296 \mathrm{~K}$ and reveals an octahedral coordination sphere composed of two pyridylpyrrolide ligands and two coordinated THF ligands. Similar to $\mathbf{F e}(\mathbf{P y r P y r r})_{2}(\mathrm{THF})_{2}$, the $\mathrm{Fe}-\mathrm{N}_{\text {pyrr }}$ distances in $\mathbf{F e}\left(\mathrm{Pyr}^{\mathrm{Me}} \mathrm{Pyrr}\right)_{2}$ (THF)2 (avg. 2.034(1) $\AA$ ) are consistent with an $\mathrm{S}=2$ complex.
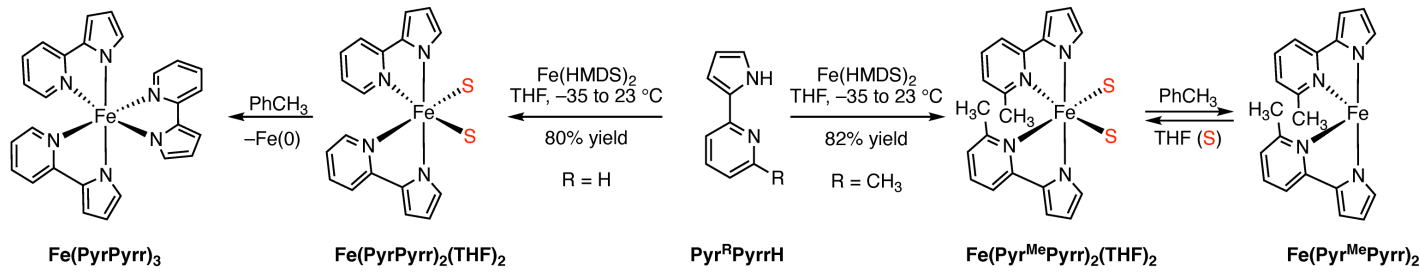

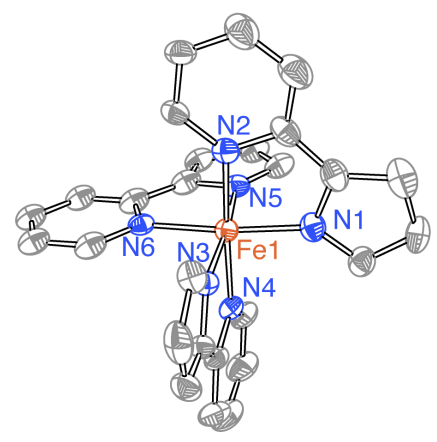

$\mathrm{Fe}($ PyrPyrr)

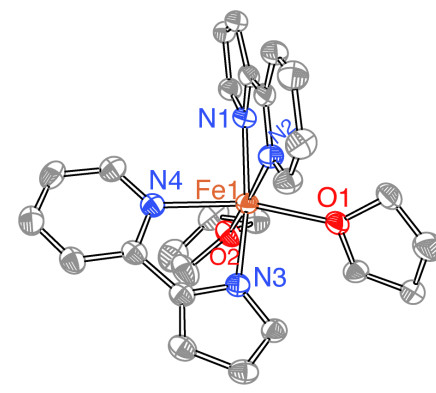

$\mathrm{Fe}(\text { PyrPyrr })_{2}(\mathrm{THF})_{2}$

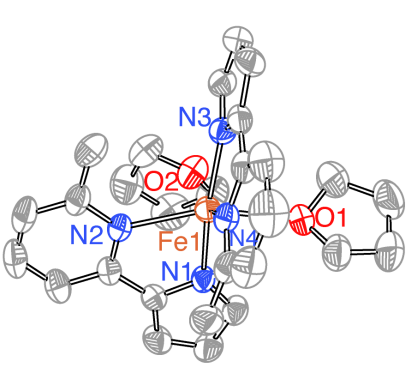

$\mathrm{Fe}\left(\mathrm{Pyr}^{\mathrm{Me} P y r r}\right)_{2}(\mathrm{THF})_{2}$

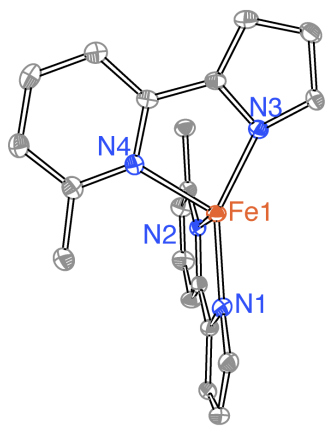

$\mathrm{Fe}_{2}\left(\text { Pyr }^{\mathrm{Me} P y r r}\right)_{2}$

Figure 6. Top: Synthesis of mononuclear Fe(II) complexes. Metallation of PyrPyrrH with Fe(HMDS $)_{2}$ affords $\mathbf{F e}(\mathbf{P y r P y r r})_{2}(\mathrm{THF})_{2}$. Attempts to access the corresponding 4-coordinate complex $\mathbf{F e}(\mathbf{P y r P y r r})_{2}$ resulted in

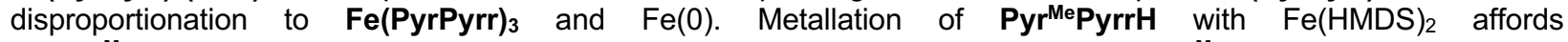
$\mathbf{F e}\left(\text { Pyr }^{\text {Me }}{ } \text { yrr }\right)_{2}(\mathrm{THF})_{2}$. Recrystallization from toluene affords 4-coordinate complex Fe(PyrMePyrr $)_{2}$, which features cisdivacant octahedral coordination at the Fe(II) center. Bottom: Displacement ellipsoid plots (50\% probability) of the

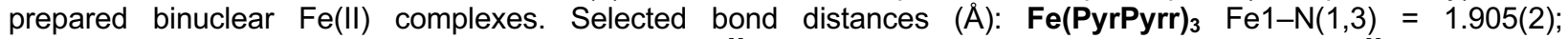
Fe(PyrPyrr $)_{2}(\text { THF })_{2} \quad$ Fe1-N(1,3) = 2.089(2); Fe(Pyr $\left.{ }^{\text {MePyrr }}\right)_{2}(\text { THF })_{2}$, Fe1-N $(1,3)=2.034(1)$; Fe(Pyr $\left.{ }^{\text {MePyrr }}\right)_{2}$, Fe1$\mathrm{N}(1,3)=1.985(2)$. 


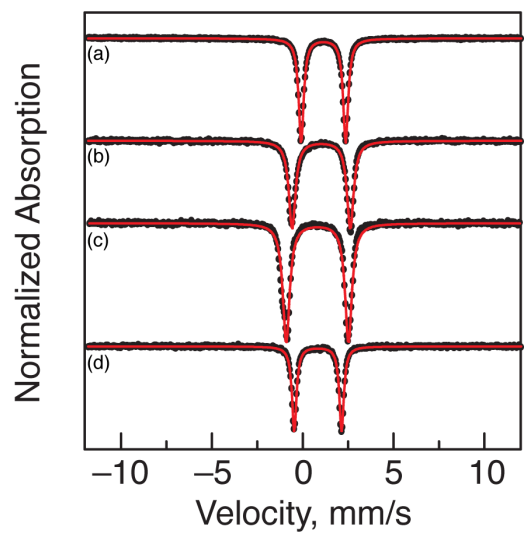

Figure 7. ${ }^{57} \mathrm{Fe}$ Mössbauer spectra of mononuclear Fe(II) complexes measured at $5 \mathrm{~K}$. All compounds display a single quadrupole doublet with $100 \%$ area of following parameters. (a) Fe(PyrPyrr) ${ }_{2}(\mathrm{THF})_{2}: \delta=1.141,\left|\Delta \mathrm{E}_{\mathrm{Q}}\right|=2.450, \gamma=$ 0.334. (b) Fe(PyrMePyrr) ${ }_{2}(\mathrm{THF})_{2}: \delta=1.020,\left|\Delta \mathrm{E}_{\mathrm{Q}}\right|=3.20, \gamma=0.443$. (c) Fe(PyrMePyrr $)_{2}: \delta=0.807,\left|\Delta \mathrm{E}_{\mathrm{Q}}\right|=3.427, \gamma=$ 0.455. (d) Fe(Pyr) $)_{2}(\text { Pyrr })_{2}: \delta=0.839,\left|\Delta \mathrm{E}_{\mathrm{Q}}\right|=2.606, \gamma=0.300$. $\delta$, isomer shift; $\left|\Delta \mathrm{E}_{\mathrm{Q}}\right|$, quadrupole splitting; $\gamma$, linewidth.

Dissolution of $\mathbf{F e}\left(\mathbf{P y r}^{\mathrm{Me}} \mathbf{P y r r}\right)_{2}(\mathbf{T H F})_{2}$ in toluene results in a red shift of the UV-vis spectral features from 470 and $496 \mathrm{~nm}$ to 485 and $511 \mathrm{~nm}$. This observation mirrors a similar red shift observed in the conversion of $\mathbf{F e}_{2}(\mathbf{B P M})_{2}(\mathbf{T H F})_{2}\left(480 \mathrm{~nm}\right.$, br) to $\mathbf{F e}_{2}(\mathbf{B P M})_{2}(493$ and $525 \mathrm{~nm})$, suggesting that a similar ligand dissociation is observed with the methylated complex. A single crystal of $\mathbf{F e}\left(\mathbf{P y r}^{\mathrm{Me}} \mathbf{P y r r}\right)_{2}$ was obtained from a toluene/pentane solution and refinement of the single-crystal X-ray data indicates that $\mathbf{F e}\left(\mathbf{P y r}{ }^{\mathrm{Me}} \mathbf{P y r r}\right)_{2}$ displays a nearly ideal CDO geometry $\left(\tau_{4}\right.$ $=0.640)$. The ${ }^{57} \mathrm{Fe}$ Mössbauer spectrum displays a single quadrupole doublet with $\delta=0.807\left(\left|\Delta \mathrm{E}_{\mathrm{Q}}\right|\right.$ $=3.42)($ Figure $7 \mathrm{c})$.

Synthesis of Model Systems. For comparison, we prepared an Fe(II) complex in which the pyrrolide and pyridyl ligands were separated (i.e., $\mathbf{F e}(\mathbf{P y r})_{2}(\mathbf{P y r r})_{2}$, Figure 8$)^{\text {. }} \mathbf{F e}(\mathbf{P y r})_{2}(\mathbf{P y r r})_{2}$ was prepared by combination of $\mathrm{Fe}(\mathrm{Pyr})_{2} \mathrm{Cl}_{2}$ and sodium pyrrolide in THF at $23{ }^{\circ} \mathrm{C}$. The ${ }^{1} \mathrm{H}$ NMR spectrum of $\mathbf{F e}(\mathbf{P y r})_{2}(\mathbf{P y r r})_{2}$ in $d_{8}$-THF displays three broad peaks from 11 to $27 \mathrm{ppm}$ and two sharper peaks at 6.64 and $6.00 \mathrm{ppm}$ (Figures S22-S23). Similar to the other monomeric Fe(II) complexes described, Evans method provide a magnetic moment of $4.6 \mu_{\mathrm{B}}$, consistent with an $\mathrm{S}=$ 2 complex. The ${ }^{57} \mathrm{Fe}$ Mössbauer spectrum displays a single quadrupole doublet with $\delta=0.839$ 
$\left(\left|\Delta \mathrm{E}_{\mathrm{Q}}\right|=2.606\right)$ (Figure 7d). A single crystal was obtained by vapor diffusion of pentane into THF solution at $-35{ }^{\circ} \mathrm{C}$. Refinement of X-ray diffraction data provides the solid-state structure illustrated in Figure 8, which reveals a tetrahedral coordination geometry for $\mathbf{F e}(\mathbf{P y r})_{2}(\mathbf{P y r r})_{2}$. CShM analysis (Table 2$)$ and $\tau_{4}$ value $\left(\tau_{4}=0.902\right)$ confirm tetrahedral coordination sphere of $\mathrm{Fe}(\mathrm{II})$ center.
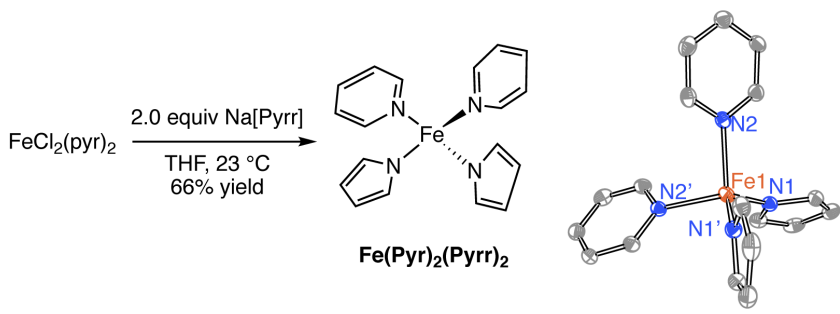

Figure 8. Synthesis of $\mathbf{F e}(\mathbf{P y r})_{2}(\mathbf{P y r r})_{2}$. Displacement ellipsoid plot drawn at $50 \%$ probability illustrates the tetrahedral coordination geometry at the Fe(II) center. Selected bond distances $(\AA)$ : Fe1-N1 = 1.990(2).

Electrochemistry. To examine the redox properties of the prepared Fe(II) complexes, cyclic voltammetry data was collected in 1,2-difluorobenzene (THF for $\mathbf{F e}(\mathbf{P y r})_{2}(\mathbf{P y r r})_{2}$ due to limited solubility in 1,2-difluorobenzene) with $\mathrm{NBu}_{4} \mathrm{PF}_{6}$ as the supporting electrolyte under an $\mathrm{N}_{2}$ atmosphere.

In general, the family of binuclear Fe(II) complexes featured poorly defined features by cyclic voltammetry in both oxidative and reductive directions (Figures S24-S29). These observations mirror those made for $\mathbf{F e}_{3}(\mathbf{T P M})_{2}{ }^{20}$ and for other Fe(II) pyrrolide complexes ${ }^{34}$ and are consistent with significant ligand-centered redox chemistry. Analysis of the mononuclear complexes reveals that $\mathbf{F e}$ (PyrPyrr)2 displays a partially reversible $\mathrm{Fe}^{\mathrm{II}} / \mathrm{Fe}^{\mathrm{I}}$ couple at $-1.22 \mathrm{~V}$ (vs. $\mathrm{Fc}^{+} / \mathrm{Fc}$ ); the observed feature is only observed when the scan is initiated in the cathodic direction (Figure 9a; see Supporting Information for additional CV data). The CDO four-coordinated Fe(Pyr $\left.{ }^{\mathbf{M e}} \mathbf{P y r r}\right)_{2}$ 
displays a partially reversible oxidation event at $-0.47 \mathrm{~V}$ vs. $\mathrm{Fc}^{+} / \mathrm{Fc}$ when the sweep begins anodically (Figure 9b).
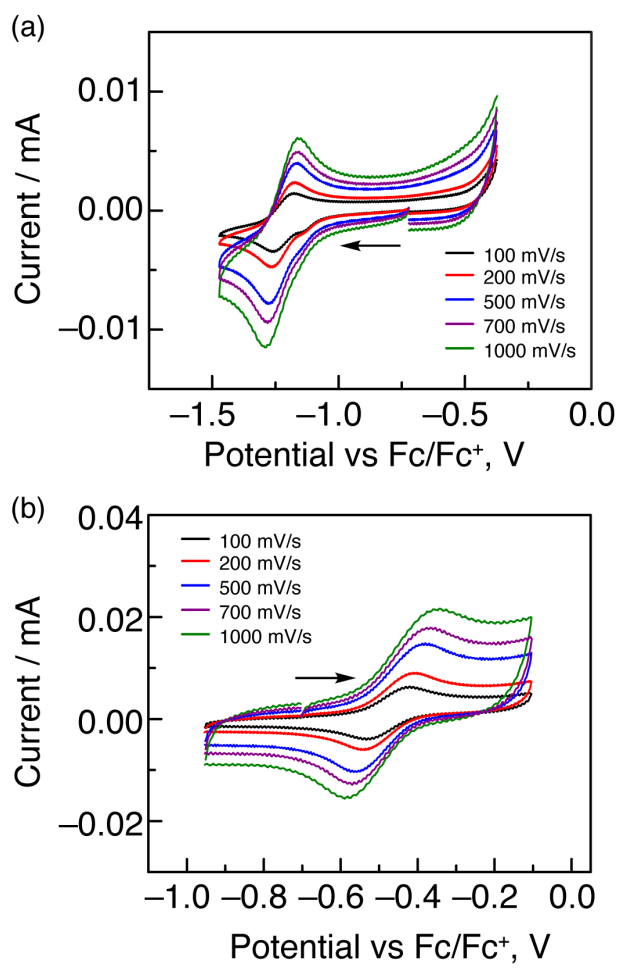

Figure 9. Cyclic voltammograms (CVs) measured in 1,2-difluorobenzne under $\mathrm{N}_{2}$ atmosphere (Potential vs. Fc/Fc ${ }^{+}$). (a) The CV of Fe(PyrPyrr) ${ }_{2}$ displays a partially reversible reduction event at $-1.22 \mathrm{~V}$, and (b) the $\mathrm{CV}$ of $\mathbf{F e}\left(\mathbf{P y r} \mathbf{M e}^{\mathrm{Me}} \mathbf{P y r r}\right)_{2}$ displays a partially reversible oxidation event at $-0.47 \mathrm{~V}$.

The observation of significant ligand contribution to the oxidation/reduction chemistry of the $\mathrm{Fe}(\mathrm{II})$ pyridylpyrrolide complexes is consistent with the computed frontier orbitals of these species. Figure 10 illustrates that HOMO and LUMO of Fe(Pyr $\left.{ }^{\mathbf{M e}} \mathbf{P y r r}\right)_{2}$ and highlights that these orbitals are predominantly pyrrollide and pyridyl centered, respectively. Similar orbital distributions have previously been described for pyridylpyrrolide complexes of first-row metals.

Computational Evaluation of Isomerization of Four-Coordinate Fe(II) Centers. To evaluate the ligand-dependent geometrical preferences of the Fe(II) complexes described above, we have evaluated the potential energy surfaces (PES) that govern isomerization of the primary 
coordination sphere in $\mathbf{F e}\left(\mathbf{P y r}^{\mathrm{Me}} \mathbf{P y r r}\right)_{2}$ and $\mathbf{F e}(\mathbf{P y r})_{2}(\mathrm{Pyrr})_{2}$. Structures were calculated using the UB3LYP functional combined with the $6-311+\mathrm{G}$ basis set on all atoms and the MDF10 effective core potential on Fe. Redundant coordinates were set for the N1-Fe-N3 angle (the angle between pyrrolide donors) and $\mathrm{N} 2-\mathrm{Fe}-\mathrm{N} 4$ angle (the angle between the pyridyl donors) to give a range of $\tau_{4}$ values while allowing for relaxation of the bond lengths and angles of the remainder of the molecule. The results of these calculations are plotted in Figure 11. The energies for the optimized structures of $\mathbf{F e}\left(\mathbf{P y r}{ }^{\mathrm{Me}} \mathbf{P y r r}\right)_{2}\left(\tau_{4}=0.70\right)$ and $\mathbf{F e}(\mathbf{P y r})_{2}(\mathbf{P y r r})_{2}\left(\tau_{4}=0.82\right)$ are set to $0 \mathrm{kcal} / \mathrm{mol}$. These calculations indicate a strong preference for the $c i s$-divacant geometry in $\mathbf{F e}_{2}\left(\mathbf{P y r}^{\mathbf{M e}} \mathbf{P y r r}\right)_{2}$ with $\tau_{4}$ values in the $0.6-0.7$ range being the lowest in energy. As the complex approaches a square planar geometry $\left(\tau_{4}=0\right)$, the energy rapidly increases. This is most likely due to a combination of a strong electronic preference for Fe to stay in a geometry conducive to high spin and large steric repulsions between ligands as they are forced into the same plane. Values for $\tau_{4}$ significantly larger than 0.7 were inaccessible due to the $82.7^{\circ}$ bite angle of the Pyr ${ }^{\mathrm{Me}} \mathbf{P y r r}$ ligand preventing tetrahedral-like geometries. In contrast, $\mathbf{F e}(\mathbf{P y r})_{2}(\mathbf{P y r r})_{2}$ shows a preference for a geometry closer to tetrahedral.
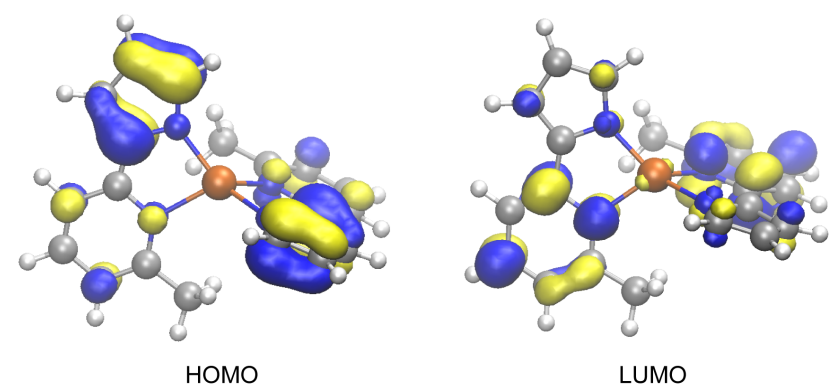

Figure 10. HOMO and LUMO of Fe(PyrMePyrr $)_{2}$ are pyrrole- and pyridyl-centered, respectively. 


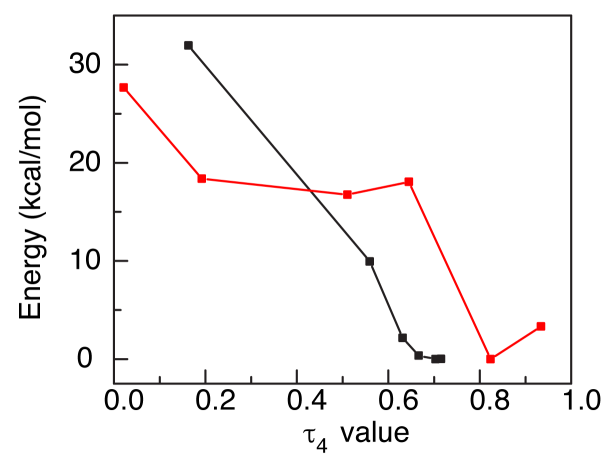

Figure 11. Computed PESs for the isomerization of $\mathrm{Fe}\left(\mathrm{Pyr}{ }^{\mathrm{Me}} \mathrm{Pyrr}\right)_{2}$ and $\mathrm{Fe}(\mathrm{Pyr})_{2}(\mathrm{Pyrr})_{2}$. Structures were generated by fixing $\mathrm{N}-\mathrm{Fe}-\mathrm{N}$ bond angles to give rise to the indicated $\tau_{4}$ values and optimizing the remainder of the structure.

\section{DISCUSSION AND CONCLUDING REMARKS}

The intimate relationship between transition metal ion coordination geometry and reactivity provides constant impetus to develop platforms that exhibit new or uncommon geometries. In the context of four-coordinate complexes, cis-divacant octahedral (CDO) coordination is rare, although the presence of cis-divacant coordination sites available for potential substrate binding and activation renders $\mathrm{CDO}$ complexes attractive for potential catalyst development (Figure 1). We had previously observed CDO coordination at Fe(II) sites in the trinuclear complex $\mathbf{F e}_{3}(\mathbf{T P M})_{2}$ assembled by metalation of the three-fold symmetric $\mathbf{H}_{3}$ TPM ligand. The origin of the peculiar coordination geometry in this trinuclear complex - ligand enforced, aggregation induced, or electronically preferred — was not clear. Further, the vacant coordination sites of the CDO Fe(II) ions in $\mathrm{Fe}_{3}(\mathrm{TPM})_{2}$ were inaccessible to substrate due to confinement within the core of the trinuclear array. To better evaluate the origins of the observed CDO geometry and to develop a suite of complexes that would provide a structural basis to evaluate the reactivity of this unique structure class, we have pursued exhaustive ligand truncation studies that have resulted in the isolation of a family of mono- and binuclear complexes that feature isostructural CDO Fe(II) ions. 
(a)
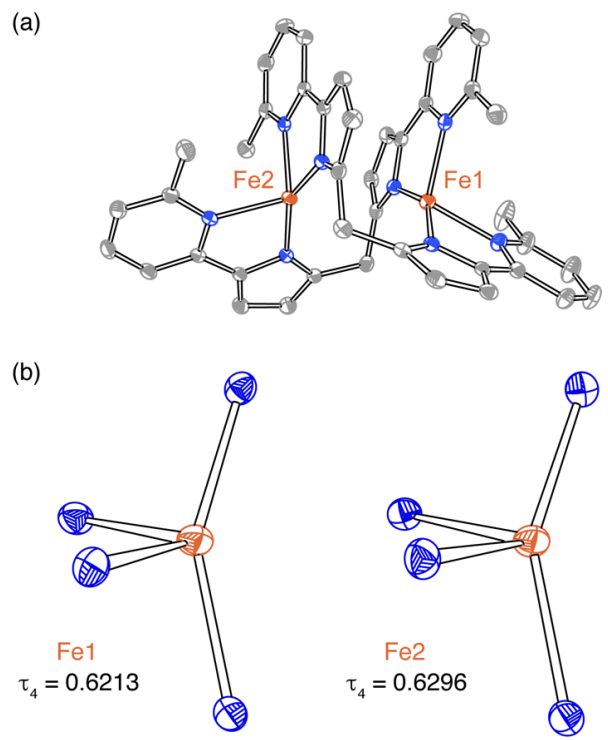

Figure 12. Displacement ellipsoid plot of $\mathrm{Fe}_{2}\left(\mathrm{BPM}^{\mathrm{Me}}\right)_{2}$. Highlight of the primary coordination sphere featuring CDO coordination at each $\mathrm{Fe}(\mathrm{II})$ center.

Excision of one of the three 2-pyridylpyrrole arms of the $\mathbf{H}_{3} \mathbf{T P M}$ ligand afforded $\mathbf{H}_{2} \mathbf{B P M}$, which supports binuclear Fe(II) complexes (Figures 3 and 4). While metalation of this ligand in THF afforded a binuclear complex $\mathbf{F e}_{2}(\mathbf{B P M})_{2}(\mathbf{T H F})_{2}$ with two sixcoordinate $\mathrm{Fe}(\mathrm{II})$ ions, the coordinated solvent ligands are labile. Dissolution in a non-coordinating solvent, such as toluene, resulted in a binuclear complex with two five-coordinate $\mathrm{Fe}(\mathrm{II})$ ions. In this complex, rearrangement of the ligand results in bridging pyrrolide ligands. Ligand methylation results in expansion of the $\mathrm{Fe}-\mathrm{Fe}$ distance and enforcement of $\mathrm{CDO}$ geometry at both $\mathrm{Fe}(\mathrm{II})$ centers; the local geometry at each of the Fe centers in $\mathbf{F e}_{2}\left(\mathbf{B P M}^{\mathrm{Me}}\right)_{2}$ are highlighted in Figure 12. Analysis of the local geometry using the $\tau_{4}$ metric was consistent with CDO coordination at each of the Fe(II) sites, which is corroborated by continuous shape analysis (Table 2).

Further ligand truncation by removal of a 2-pyridylpyrrole arm from the $\mathbf{H}_{2} \mathbf{B P M}$ ligand series provides access to bidentate ligands PyrPyrrH and $\mathbf{P y r}^{\mathrm{Me}} \mathbf{P y r r H}$. Metallation of each of these in coordinating solvents provides access to monomeric, six-coordinate $\mathrm{Fe}(\mathrm{II})$ species in which solvent ligands occupy mutually cis coordination sites (Figure 6). Again, dissolution of these complexes in non-coordinating solvents results in labilization of the bound THF ligands to generate unsaturated Fe(II) complexes. In the case of Fe(PyrPyrr)2, disproportionation to Fe(PyrPyrr) $)_{3}$ and $\mathrm{Fe}(0)$ prevents isolation of the unsaturated monomer. In contrast, THF 
dissociation from $\mathbf{F e}\left(\mathbf{P y r}^{\mathrm{Me}} \mathbf{P y r r}\right)_{2}$ (THF)2 affords four-coordinate CDO complex Fe(Pyr $\left.{ }^{\text {Me Pyrr }}\right)_{2}$. Comparison of the primary coordination sphere before and after THF dissociation reveals remarkably little structural rearrangement accompanies ligand dissociation (Figure 13). The Fe(II) center in $\mathbf{F e}\left(\mathbf{P y r} \mathbf{M e}^{\mathrm{Me}} \mathbf{P y r r}\right)_{2}$ is rigorously CDO by analysis of the $\tau_{4}$ metric. In addition, the $\mathrm{Fe}(\mathrm{II})$ ion in $\mathbf{F e}\left(\mathbf{P y r} \mathbf{M}^{\mathrm{Me}} \mathbf{P y r}\right)_{2}$ shows similar coordination structure of Fe to the four-coordinate binuclear complex, $\mathbf{F e}_{2}\left(\mathbf{B P M}^{\mathrm{Me}}\right)_{2}$ : Both complexes feature $\mathrm{CDO}$ coordination and the Fe- $\mathrm{N}_{\text {pyrr }}$ distances in $\mathbf{F e}\left(\mathbf{P y r} \mathbf{r}^{\mathrm{Me}} \mathbf{P y r r}\right)_{2}(1.985(2) \AA)$ are comparable to that of $\mathbf{F e} \mathbf{2}_{2}\left(\mathbf{B P M}^{\mathrm{Me}}\right)_{2}$ (1.997(1) $\AA$ ). The formation of two vacant sites by solvent dissociation is notable because previous studies in related pyrrolide complexes has resulted in five-coordinate, mono-solvento complexes. ${ }^{35}$

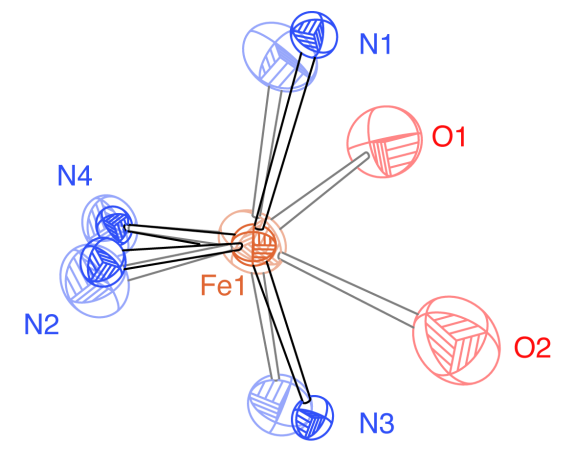

Figure 13. Overlay of the primary coordination spheres of $\mathbf{F e}\left(\mathrm{BPM}^{\mathrm{Me}}\right)_{\mathbf{2}}(\mathrm{THF})_{2}$ (faded) and $\mathrm{Fe}\left(\mathrm{BPM}^{\mathrm{Me}}\right)_{\mathbf{2}}$, which highlights the minimal structural reorganization that accompanies THF dissociation and formation of the CDO Fe(II) ion.

To evaluate the origin of the observed CDO geometry, we prepared $\mathbf{F e}(\mathbf{P y r})_{2}(\mathbf{P y r r})_{2}$ in which the aforementioned 2-pyridylpyrrolide ligands were separated into their constituent monodentate donors (Figure 8). In contrast to the suite of complexes prepared from chelating ligands, $\mathbf{F e}(\mathbf{P y r})_{2}(\mathbf{P y r r})_{2}$ displays tetrahedral coordination $\left(\tau_{4}=0.902\right)$ about the $\mathrm{Fe}(\mathrm{II})$ ion. This observation indicates that the electronically preferred geometry of $\mathrm{Fe}(\mathrm{II})$ with two pyridyl and two pyrrolide donors is tetrahedral and suggests that ligand chelation is responsible for the observed geometrical preferences in the obtained CDO complexes. The relative coordination preferences of monodentate and chelating bidentate donors was 
evaluated by examining the potential energy surfaces that dictate the ligand-dependent coordination geometries of $\mathrm{Fe}(\mathrm{II})$ (Figure 11). Consistent with experiment, the potential energy surface for monodentate donors prefers tetrahedral coordination whereas the bidentate potential energy surface prefers CDO. The consistency of these computations with experiment indicates that the observed geometries do not arise due to crystal packing. Further, in the case of complex $\mathbf{F e}\left(\mathbf{P y r}{ }^{\mathrm{Me}} \mathbf{P y r r}\right)_{2}$, the potential energy surface is fairly flat in the vicinity of CDO coordination, which indicates that small structural perturbations have a significant impact of the observed coordination geometry. We speculate that the disparity in geometry between monodentate donors (i.e., $\left.\mathbf{F e}(\mathbf{P y r})_{2}(\mathbf{P y r r})_{2}\right)$ and bidentate donors (i.e., $\mathbf{F e}\left(\mathbf{P y r}{ }^{\mathrm{Me}} \mathbf{P y r r}\right)_{2}$ arises because the chelating ligand has a narrow bite angle $\left(\sim 83^{\circ}\right)$ that cannot be accommodated in more tetrahedral arrangements.

Access to a family of Fe complexes that display rigorous $\mathrm{CDO}$ coordination about the metal center provides an opportunity to evaluate the activity of these sites towards substrate binding and activation. Of particular note is the observation that while Fe pyrrolides often display liganddominated, irreversible electrochemistry, Fe(Pyr $\left.{ }^{\text {Me Pyrr) }}\right)_{2}$ displays a reversible $\mathrm{Fe}(\mathrm{III}) / \mathrm{Fe}(\mathrm{II})$ couple. Combined with the available open coordination sites, this observation suggests $\mathbf{F e}\left(\mathbf{P y r}^{\mathrm{Me}} \mathbf{P y r r}\right)_{2}$ may be a good candidate for substrate engagement. Ongoing work is aimed at pursuing both the broader synthetic chemistry of CDO geometries with other transition metals and to the development of group transfer catalysis with CDO Fe(II) catalysts.

\section{Acknowledgement}

The authors acknowledge Nattamai Bhuvanesh and Gayle Bornovski for assistance with crystallographic and electrochemical experiments, respectively. In addition, the authors acknowledge financial support from the U.S. Department of Energy (DOE), Office of Science, 
Office of Basic Energy Sciences, Catalysis Program (DE-SC0018977), the Welch Foundation (A-

1907), and an Alfred P. Sloan Fellowship to DCP and the National Institutes of Health

(GM127021) to PAL.

\section{References}

1. Kochem, A.; Carrillo, A.; Philouze, C.; van Gastel, M.; du Moulinet d'Hardemare, A.; Thomas, F., Copper(II)Coordinated $\alpha$-Azophenols: Effect of the Metal-Ion Geometry on Phenoxyl/Phenolate Oxidation Potential and Reactivity. Eur. J. Inorg. Chem. 2014, 2014, 4263-4267.

2. Muthuramalingam, S.; Anandababu, K.; Velusamy, M.; Mayilmurugan, R., Benzene Hydroxylation by Bioinspired Copper(II) Complexes: Coordination Geometry versus Reactivity. Inorg. Chem. 2020, 59, 5918-5928.

3. Combariza, M. Y.; Vachet, R. W., Effect of Coordination Geometry on the Gas-Phase Reactivity of Four-Coordinate Divalent Metal Ion Complexes. J. Phys. Chem. A 2004, 108, 1757-1763.

4. Favas, M. C.; Kepert, D. L., Aspects of the Stereochemistry of Four-Coordination and Five-Coordination. In Progress in Inorganic Chemistry, 1980; pp 325-463.

5. Cirera, J.; Ruiz, E.; Alvarez, S., Stereochemistry and Spin State in Four-Coordinate Transition Metal Compounds. Inorg. Chem. 2008, 47, 2871-2889.

6. Hawrelak, E. J.; Bernskoetter, W. H.; Lobkovsky, E.; Yee, G. T.; Bill, E.; Chirik, P. J., Square Planar vs Tetrahedral Geometry in Four Coordinate Iron(II) Complexes. Inorg. Chem. 2005, 44, 3103-3111.

7. Vela, J.; Cirera, J.; Smith, J. M.; Lachicotte, R. J.; Flaschenriem, C. J.; Alvarez, S.; Holland, P. L., Quantitative Geometric Descriptions of the Belt Iron Atoms of the Iron-Molybdenum Cofactor of Nitrogenase and Synthetic Iron(II) Model Complexes. Inorg. Chem. 2007, 46, 60-71.

8. Muetterties, E. L.; Guggenberger, L. J., Idealized Polytopal Forms. Description of Real Molecules Referenced to Idealized Polygons or Polyhedra in Geometric Reaction Path Form. J. Am. Chem. Soc. 1974, 96, 1748-1756.

9. Murray-Rust, P.; Buergi, H. B.; Dunitz, J. D., Chemical Reaction Paths. V. $\mathrm{SN}_{1}$ Reaction of Tetrahedral Molecules. J. Am. Chem. Soc. 1975, 97, 921-922.

10. Vela, J.; Stoian, S.; Flaschenriem, C. J.; Münck, E.; Holland, P. L., A Sulfido-Bridged Diiron(II) Compound and Its Reactions with Nitrogenase-Relevant Substrates. J. Am. Chem. Soc. 2004, 126, 4522-4523.

11. Shinji, T.; Michinori, O., Structure of Intramolecular Boron-Amine Complexes and Proposal of Tetrahedral Character for Correlation between Molecular Structure and Barrier to Dissociation of the N-B Bonds. Bull. Chem. Soc. Jpn. 1992, $65,1832-1840$.

12. Hutchison, A. R.; Mitra, A.; Atwood, D. A., The Four Coordinate Geometric Parameter: A New Quantification of Geometry for Four Coordinate Aluminum and Gallium. Main Group Chemistry 2005, 187-200.

13. Yang, L.; Powell, D. R.; Houser, R. P., Structural Variation in Copper(I) Complexes with Pyridylmethylamide Ligands: Structural Analysis with a New Four-Coordinate Geometry Index, $\tau_{4}$. Dalton Trans. 2007, 955-964.

14. Pinsky, M.; Avnir, D., Continuous Symmetry Measures. 5. The Classical Polyhedra. Inorg. Chem. 1998, 37, 5575-5582.

15. Keinan, S.; Avnir, D., Continuous Symmetry Analysis of Tetrahedral/Planar Distortions. Copper Chlorides and Other $\mathrm{AB}_{4}$ Species. Inorg. Chem. 2001, 40, 318-323.

16. Keinan, S.; Avnir, D., Studies in Copper(II) Complexes: Correlations Between Quantitative Symmetry and Physical Properties. J. Chem. Soc., Dalton Trans. 2001, 941-947.

17. Searles, K.; Fortier, S.; Khusniyarov, M. M.; Carroll, P. J.; Sutter, J.; Meyer, K.; Mindiola, D. J.; Caulton, K. G., A cisDivacant Octahedral and Mononuclear Iron(IV) Imide. Angew. Chem. Int. Ed. 2014, 53, 14139-14143.

18. Kurup, S. S.; Wannipurage, D.; Lord, R. L.; Groysman, S., Tying the Alkoxides Together: an Iron Complex of a New Chelating bulky Bis(alkoxide) Demonstrates Selectivity for Coupling of Non-Bulky Aryl Nitrenes. Chem. Commun. 2019, 55, 10780-10783.

19. Bellow, J. A.; Fang, D.; Kovacevic, N.; Martin, P. D.; Shearer, J.; Cisneros, G. A.; Groysman, S., Novel Alkoxide Cluster Topologies Featuring Rare Seesaw Geometry at Transition Metal Centers. Chem. Eur. J. 2013, 19, 1222512228. 
20. Hyun, S.-M.; Upadhyay, A.; Das, A.; Burns, C. P.; Sung, S.; Beaty, J. D.; Bhuvanesh, N.; Nippe, M.; Powers, D. C., Kinetic versus Thermodynamic Metalation Enables Synthesis of Isostructural Homo- and Heterometallic Trinuclear Clusters. Chem. Commun. 2020, 56, 5893-5896.

21. Rieth, R. D.; Mankad, N. P.; Calimano, E.; Sadighi, J. P., Palladium-Catalyzed Cross-Coupling of Pyrrole Anions with Aryl Chlorides, Bromides, and Iodides. Org. Lett. 2004, 6, 3981-3983.

22. Oliver, J. D.; Mullica, D. F.; Hutchinson, B. B.; Milligan, W. O., Iron-Nitrogen Bond Lengths in Low-Spin and HighSpin Iron(II) Complexes with Poly(pyrazolyl)borate Ligands. Inorg. Chem. 1980, 19, 165-169.

23. Greenaway, A. M.; Sinn, E., High-Spin and Low-Spin $\alpha$-Picolylamine Iron(II) Complexes. Effect of Ligand Reversal on Spin State. J. Am. Chem. Soc. 1978, 100, 8080-8084.

24. Eisenhart, R. J.; Rudd, P. A.; Planas, N.; Boyce, D. W.; Carlson, R. K.; Tolman, W. B.; Bill, E.; Gagliardi, L.; Lu, C. C., Pushing the Limits of Delta Bonding in Metal-Chromium Complexes with Redox Changes and Metal Swapping. Inorg. Chem. 2015, 54, 7579-7592.

25. Cotton, F. A.; Murillo, C. A.; Walton, R. A., Multiple Bonds between Metal Atoms. Springer Science: New York, 2005.

26. Pauling, L., Atomic Radii and Interatomic Distances in Metals. J. Am. Chem. Soc. 1947, 69, 542-553.

27. Addison, A. W.; Rao, T. N.; Reedijk, J.; van Rijn, J.; Verschoor, G. C., Synthesis, Structure, and Spectroscopic Properties of Copper(Ii) Compounds Containing Nitrogen-Sulphur Donor Ligands; The Crystal and Molecular Structure of Aqua [1,7-bis(N-methylbenzimidazol-2'-yl)-2,6-dithiaheptane] copper(II) perchlorate. J. Chem. Soc., Dalton Trans. 1984, 134-91356.

28. Conceptually similar to $t_{4}$ values, $t_{5}$ values are descriptors of the coordination geometries of 5-coordinate complexes.

29. A molecule of $\mathrm{PhCH}_{3}$ was located in the unit cell. This solvent molecule was carried over from previous synthetic manipulations.

30. Werncke, C. G.; Bouammali, M.-A.; Baumard, J.; Suaud, N.; Martins, C.; Guihéry, N.; Vendier, L.; Zheng, J.; Sortais, J.-B.; Darcel, C.; Sabo-Etienne, S.; Sutter, J.-P.; Bontemps, S.; Pichon, C., Ising-type Magnetic Anisotropy and Slow Relaxation of the Magnetization in Four-Coordinate Amido-Pyridine Fe ${ }^{\mathrm{II}}$ Complexes. Inorg. Chem. 2016, 55, 1096810977.

31. Casanova, D.; Cirera, J.; Llunell, M.; Alemany, P.; Avnir, D.; Alvarez, S., Minimal Distortion Pathways in Polyhedral Rearrangements. J. Am. Chem. Soc. 2004, 126, 1755-1763.

32. Cirera, J.; Ruiz, E.; Alvarez, S., Shape and Spin State in Four-Coordinate Transition-Metal Complexes: The Case of the $\mathrm{d}_{6}$ Configuration. Chem. Eur. J. 2006, 12, 3162-3167.

33. Nishida, Y.; Kino, K.; Kida, S., Crystal Structures of Low- and High-Spin Iron(III) Complexes with Quadridentate Schiff Bases. J. Chem. Soc., Dalton Trans. 1987, 1157-1161.

34. Sazama, G. T.; Betley, T. A., Ligand-Centered Redox Activity: Redox Properties of 3d Transition Metal Ions Ligated by the Weak-Field Tris(pyrrolyl)ethane Trianion. Inorg. Chem. 2010, 49, 2512-2524.

35. Searles, K.; Das, A. K.; Buell, R. W.; Pink, M.; Chen, C.-H.; Pal, K.; Morgan, D. G.; Mindiola, D. J.; Caulton, K. G., 2,2'-Pyridylpyrrolide Ligand Redistribution Following Reduction. Inorg. Chem. 2013, 52, 5611-5619. 